\title{
Socially Networked Heterogeneity: The Influence of WhatsApp as a Social Networking Site on Polarisation in Kenya
}

\begin{tabular}{|l|l|}
\hline Amos Kibet & Stephen Ward \\
University of Salford, United Kingdom & University of Salford, United Kingdom \\
Kibetams@ gmail.com & S.J.Ward@ salford.ac.uk
\end{tabular}

\section{Abstract}

Using a cross-sectional survey of two sampled counties in Kenya, this article analyses whether social networking sites reflect social network heterogeneity. It then examines how social network heterogeneity influences polarisation in Kenya. Three types of polarisation are examined: party, ethnic and ideological (around county resources). The study focuses specifically on the public WhatsApp platform (the most popular SNS in Kenya). To assess this empirical data, theoretical perspectives are drawn from the literatures on incidental and selective exposure and their impact on political polarisation. The findings indicate that the randomised composition of a WhatsApp group through public links indeed reflects social network heterogeneity. The findings further show that posting political news, obtaining political news and commenting on political news influence social network heterogeneity to some degree. This social network heterogeneity was also found to influence all three (party, ideological and ethnic) types of polarisation in varying but significant degrees.

Keywords: heterogeneity; polarisation; social networking sites; political discussion

\section{Introduction}

Scholars of communication, social movements and political participation have studied the role of social networking sites (SNSs) as possible instigators of political polarisation (Ji 2017; Loader, Vromen, and Xenos 2014; Osatuyi 2013; Valenzuela, Arriagada, and Scherman 2012). Baek (2015) argues that due to its nature and characteristics, social networking sites provide ideal platforms for examining correlations between exposure to political communications and the degree of polarisation. This is because they are platforms of information exchange, social interaction and political discussion (Buglass et al. 2017; Thelwall 2009). The critical question at the heart of many such studies has been whether social networking platforms intensify or ameliorate levels of polarisation in various sociopolitical contexts (Arceneaux and Johnson 2010; Pattie and Johnston 2016). Two competing perspectives have emerged both with fairly distinct diagnosis and conclusions. 
The first states that individuals, through the process of selective exposure, are more likely to seek like-minded viewpoints. Consequently, they tend to avoid divergent political perspectives (Arceneaux and Johnson 2010; Pattie and Johnston 2016) and strengthen preexisting opinions and prejudices (Stroud 2010). This phenomenon is further aggravated by features of social networking sites which serve as echo chambers of individuals' preferred opinions (Garrett, Carnahan, and Lynch 2013). The second, alternative, perspective argues that social networking sites actually expose individuals to diverse views which then serve to increase tolerance and moderate their political opinions and ideological polarisation (Ahn 2012; Nir 2011). Research on social networking sites has shown that they afford users adaptable and flexible communication opportunities that would otherwise be lacking in ordinary social and political settings (Min 2010).

Our study extends the boundaries of existing research both technologically and geographically by examining these perspectives in the context of WhatsApp discussions on local Kenyan politics - a country seen as having high levels of polarisation. The research sought to understand the following: how WhatsApp, as a social networking site, is reflective of the social network heterogeneity of its users; how usage of social networking sites, (posting, obtaining and commenting on political news), influences social network heterogeneity; and whether any association exists between social network heterogeneity and polarisation. These objectives were addressed by employing a cross-sectional survey of young voters in Nairobi and Nakuru counties.

The study concludes that both perspectives outlined above are to some extent tenable. Whether individuals use social networking sites as echo chambers for selective exposure or as platforms for enhancing diversity of opinions and perspectives depends on a number of factors. These include, first, the interactive dynamics within the social networking sites, an example being the SNSs platform's affordances/features and how individuals can join, access or connect with heterogeneous others. The second factor concerns the discursive culture characterised by group dynamics and how participants interact in the context of such dynamics (Pattie and Johnston 2016; Stroud 2010).

\section{Contextual Perspective of Polarisation in Kenya}

Polarisation in Kenya is largely founded on the colonial indiscriminate creation of states during the scramble for Africa (Branch and Cheeseman 2006). Different ethnic groups with 
varied forms of culture, language and sociocultural beliefs were huddled together and then expected to establish integrated nation states (Zeleza 2010). Kenya is, therefore, a multiethnic, multi-cultural, multi-religious and multi-racial society. In addition, the British administrative policy of "divide and rule"-playing one ethnic community off against another-also formed part of the entrenched post-independence culture (Kanyinga 2014). The situation was further aggravated after independence when leaders of independent Kenya adopted the same pragmatic, divisive and often ruinous policies established by colonialists (Berg-Schlosser 1982; Kanyinga 2014). Ideological differences between the KANU and KADU parties, ethnic fragmentation, unaddressed historical injustices and inequality in resource distribution became Kenya's bane (Berg-Schlosser 1982; Cheeseman, Lynch, and Willis 2014; Kabiri 2014). The presidential system promoted hotly contested elections and facilitated a climate of zero-sum contestation where the winner takes all in terms of state resources (Carrier and Kochore 2014). Cheeseman, Lynch, and Willis (2014) note how political elites exploited the marginalisation, exclusion and perceived state discrimination to incite violence around election periods. Sporadic violence resulting from ethnic cleavages have often accompanied Kenya's quest for justice, retribution and national healing (Hassan 2015). The post-election violence that followed the 2007/8 General Election nearly saw the nation torn apart (Halakhe 2013). Looking back at this election, there is widespread agreement that the introduction of democratic competition in societies divided by race, ethnicity, or religion can increase the risk of inter-communal violence (Mutahi and Kimari 2017). Moreover, it can be argued that because of the strong association between ethnicity and trust, ethnic communities associated with the leading parties internalise messages offered by distinct sets of political elites during campaigns. The result is that negative ethnic appeals exacerbate divisions across communities during such periods (Kanyinga 2014). As a result, a new constitutional dispensation was prescribed as a panacea to Kenya's historical injustices, inequality, political marginalisation and malfunctioning institutions (World Bank 2012). This prescription was part of recommendations made by a post-election commission (Kagwanja and Southall 2009). One of the key proposed solutions was the devolution of political powers and decentralisation of decision making to counties. According to Kramon and Posner (2015), the challenges of centralisation gradually led to serious and corrosive grievances about citizen exclusion from the governance process (Long, Kanyinga, and Ferree 2013). Looking at the 2013 and 2017 general elections, it is clear that polarisation still exists within the state polity. Furthermore, this may have been worsened by the resource governance processes at the county level (CRECO 2014). The amplification of such polarisation is still 
evident in social networking sites in Kenya (Kamau 2017). The question, therefore, is whether the composition and discussions in such digital platforms reflect, instigate or merely project sociopolitical polarisation in Kenya.

\section{Technology, Polarisation and the Rise of WhatsApp in Kenya}

The possibility of technological developments adding to traditional polarisation in Kenya is increasingly important to consider given the significant growth of Internet platforms in the past decade. According to the Communication Authority of Kenya, mobile phone penetration is over 90 per cent (2017) while Internet penetration in 2017 stood at 89.4 per cent (Africa Internet Users 2017). Kenya's broadband market has been transformed by a combination of increased investments in network upgrades (Souter and Kerrets-Makau 2012) alongside the landing of four fibre-optic submarine cables (Africa Internet Users 2017). Increased international bandwidth resulted in a decrease in wholesale prices, which helped make broadband services affordable for mass audiences (Fraenkel 2014). The rapid upward trend in Internet penetration may be attributed to increased access to low-cost smartphones (Souter and Kerrets-Makau 2012), and the competitive pricing of data bundles by mobile phone companies (Africa Internet Users 2017). Global technology giants such as Google, Samsung and Microsoft have all established a presence in Kenya in recent years, owing to its modernised ICT environment (Munyua 2016). Since 2012, the social media environment has witnessed the exponential growth of one new entrant in particular-WhatsApp - now the most popular social networking platform. One report (BAKE 2017) indicates that in 2018, WhatsApp had more than 12 million users in Kenya, compared to seven million for Facebook and 2.2 million for Twitter (CA 2018). The growth of WhatsApp groups can be both public and private. The former is normally where the link is posted on popular websites for public access and joining. The latter is where access is limited to links to any existing group member.

Social media platforms, such as WhatsApp, have already become key sources of news for young people especially (BAKE 2017). Traditionally, such younger citizens rarely pay attention to news disseminated from the mainstream media outlets (Otieno and Mukhongo 2013). However, the interface between mainstream media and social media discussion is increasingly evident even in new social media platforms. Whatsapp has joined other social networking sites by providing a myriad of discussion groups and digital public spaces for political and social issue discussion. Political news stories posted from both online and 
mainstream media outlets in the WhatsApp groups often generate huge online discussions. Nevertheless, research tends to indicate that only interested, pro-active and already engaged individuals are inclined or motivated to join such groups (Brites 2014; Enjolras, SteenJohnsen, and Wollebæk 2013; Fabbrini 2013; Kim and Kim 2017). Hence, new social media platforms are generally seen as strengthening the position of the already engaged to further participate in political debates and discussion rather than reaching new audiences for politics. In the case of Kenya specifically, though, there has been limited empirical research conducted on the rise of SNS and its potential impact on political discussion. Below we set out a series of hypotheses drawing on existing theoretical work to examine the potential of SNS in terms of network heterogeneity and polarisation in Kenya.

\section{Social Networking Sites and Social Network Heterogeneity}

First hypothesis: WhatsApp as a social networking site is reflective of the social network heterogeneity of its users.

The premise of this hypothesis is that when social networking sites are characterised by a high degree of social networking heterogeneity, incidental exposure becomes inevitable. Consequently, selective exposure to information is minimised or made impossible. Following the proliferation of social networking sites, varied propositions have been promoted regarding the individual practice of selective exposure (Zhang et al. 2010; Ponder and Haridakis 2015) and how it shapes the formation of public opinions including the potential for polarisation.

Cognitive dissonance is one of the theoretical propositions used to explain the issue of selective exposure (Garrett, Carnahan, and Lynch 2013). Studies have, indeed, indicated that individuals are more likely to select sources of information consistent with their partisan perspectives and political predispositions (Lee et al. 2014; Wicks, Wicks, and Morimoto 2014). They also are more likely to seek out political information about issues that they are interested in. Various scholars have argued that when individuals are continuously exposed to like-minded political information congruent with their existing ideologies, the desire to remain with homogeneous social networks is also heightened (Zhang et al. 2010; Lee et al. 2014; Ponder and Haridakis 2015). This is, according to Zhang et al. (2010), in part facilitated by the availability and flexibility in selecting political information in new media. If citizens are exposed to less diverse political communications then the ramifications for democracy are potentially damaging. For instance, Sunstein suggests that the use of SNSs 
will eventually lead to what he calls "isolated enclaves of like-minded individuals" $(2007,4)$. Similarly, Brynjolfsson and Van Alstyne (2007) argue that such SNSs participants through a process called cyber-balkanisation establish echo chambers that discuss, process and interact based on their selected issues and individuals. In short, the fear is that continuing exposure to like-minded ideologies risks fragmenting society into competing and polarised factions which become less accommodative of divergent opinions and acrimonious towards those who hold contrary political opinions (Pattie and Johnston 2016; Stroud 2010).

Despite these well-articulated fears, though, some empirical studies have indicated that social networking sites have precisely the opposite effects and instead increase the probability that individuals will encounter diverse political information and viewpoints (Ponder and Haridakis 2015; Messing and Westwood 2014). Research has also suggested that even though individuals might well seek out opinions that are in line with their own, this does not entail systematically and actively sacrificing exposure to divergent political opinions. Nir (2011) found that individuals are more likely, in social networking sites, to come across political divergence even when the intention to do so does not exist. The structural advantages and features of social networking sites include their porous borders (Loader and Mercea 2011) and blurred boundaries (Brundidge 2010). Such porosity can, however, be limited by platform features such as "unfriending" individuals, blocking people bearing divergent views (Kim, Hsu, and de Zúñiga 2013), or exiting groups in the case of WhatsApp. Nevertheless, when SNSs users expand their sphere of friendship beyond their immediate communities the probability of encountering diversity of exposure is increased (Bojanowski and Corten 2014).

Whilst selective exposure is often seen as crucially important, additional research has focused on the response to information received. Such studies have indicated that individuals sometimes reject others based on their political orientations on social media (Pénard and Poussing 2010; Weeks et al. 2017; Yamamoto and Kushin 2014). Alternatively, when users are exposed to divergent opinions on social media, they typically ignore such posts (Loader, Vromen, and Xenos 2014; Vissers and Stolle 2014). Studies have also found a positive correlation between conventional (offline) social networks, the heterogeneity of such networks and exposure to diverse perspectives (Garrett, Carnahan, and Lynch 2013; Price et al. 2002). Our research here, therefore, seeks to establish if this exposure to diverse information in social networking sites is incidental to social network heterogeneity. 


\section{Mediatory Effects of SNSs and Social Network Heterogeneity}

Second hypothesis: Social networking site usage, including posting political news, obtaining political news and commenting about political news, influences social network heterogeneity.

The premise of this hypothesis is that when social networking sites consist mainly of a homogenous category of individuals, the consumption, discussion and posting of news within the groups incidentally exposes them to heterogeneous opinions. This creates a form of social network heterogeneity based on information exposure. According to Eveland and Hively (2009), frequent users of social networking sites are more likely to have deeply heterogeneous networks online. As they engage in political activities that demand interactions, individuals exchange information and express opinions with diverse people in ways that create connections and bonds (Buglass et al. 2016). Through SNSs, individuals can engage in various activities of information exchange including socialisation, entertainment and political discussions. Informational exchanges on social media such as posting messages, commenting and political discussions have been predicted to then enhance the diversity of information exchanged (Eveland and Hively 2009; Kim and Chen 2015; Scheufele et al. 2006). The explanation is that SNSs function as information hubs allowing users to exchange and share information (Zhang et al. 2010). Frequent users of SNSs have a tendency to be involved more in discursive informational exchange and connection (Pattie and Johnston 2016). The basis of this argument is that news shared on those platforms originates from a multiplicity of sources on varied political and public affairs which SNS users can easily pick and discuss (Buglass et al. 2016). Such discussion then further teases out diverse perspectives that facilitate exposure to multiple viewpoints. This can be done by "liking" the comments, adding to the trail of comments and interjections about the issues being discussed. Some researchers (Brundidge 2010; Kim, Chen, and de Zúñiga 2013; Lee et al. 2014) have found that frequent participation in political discussion on social networking sites potentially leads to more heterogeneous networks. This is what Weeks et al. (2017) term incidental exposure. Moreover, it has been suggested that social and political issues elicit the most diverse contribution from SNSs users (Rojas and Puig-i-Abril 2009). For example, it has been found that using Facebook to post news, express opinions and to socialise with friends influenced the extent to which individuals were willing to change their habits (Zhang et al. 2010) and engage in more political discussion especially with diverse "others" (Garrett, Carnahan, and Lynch 2013). Further studies have, indeed, confirmed that political messaging affects the relationship between use of SNSs and the deliberate exposure to political heterogeneity 
(Pattie and Johnston 2016). Our study here notes that where social networking sites have an element of social network heterogeneity, then more interaction with news through posting, commenting and discussion enhances further heterogeneity.

\section{Social Network Heterogeneity and Polarisation}

Third hypothesis: An association exists between social network heterogeneity and polarisation (ethnic, party and ideological polarisation).

The basis of this hypothesis is that when a high degree of social network heterogeneity exists in a SNS, then less ethnic, party and ideological polarisation should be experienced. The relationship between the use of media and political polarisation has been found to revolve around exposure to similar or dissimilar viewpoints (Kim and Kim 2017; Kim and Chen 2015; Rathnayake and Winter and 2017; Vaccari et al. 2015). Furthermore, the more individuals were exposed to diverse political perspectives, the more accommodating they were to politically diverse "others" (Vaccari et al. 2015). The majority of the literature that has studied political polarisation has focused on an individual's partisan political affiliations (Gustafsson 2012) and their patterns of media use (Lee et al. 2014). Other scholars have also focused on the structure and nature of societies and conventional social networks as one key influence of political polarisation (Stroud 2010). To explain attitudinal polarisation among individuals, the structure of social networks tends to influence their informational environment through the diffusion of political messages (Ljepava et al. 2013). Individuals who exist in heterogeneous environments where exchange of information occurs among diverse people are more exposed to diverse perspectives (Xu, Liu, and You 2011).

Research looking at the influence of exposure to dissimilar opinions on political polarisation has elicited mixed findings and reactions. There are various groups of theoretical positions in this regard. The first one proposed by deliberative theorists posits that communications in diverse settings has a depolarising influence on individuals (Carpini., Cook, and Jacobs 2004; Kim 2015). These theorists argue that the sharing of dissimilar opinions raises political disagreements, which in turn challenges individuals to engage in a deliberative critical thinking process (Carpini, Cook, and Jacobs 2004). Consequently, individuals are challenged to take opposing views into consideration with the result that it fosters political comprehension of diverse perspectives (Binder et al. 2009). According to Weir, Toolan, and Smeed (2011), this eventually induces convergence of ideology through the modification of 
political views. Notably, empirical research has suggested that exposure to different viewpoints tends to enhance awareness, and tolerance, of the legitimate arguments regarding opposite political perspectives (Johnson et al. 2013; Wicks, Wicks, and Morimoto 2014). It has also been claimed that heterogeneous social networks depolarise individuals' attitudes as regards political parties in established democracies like the UK and US (Osatuyi 2013).

The second, alternative, perspective is confirmation bias. This is where individuals accord unequal weights and attention to information that corroborates their initial positions and beliefs (Lee et al. 2014; Wojcieszak 2010). Consequently, exposure to dissimilar viewpoints simply magnifies pre-existing political orientation and produces further extreme positions (Chong and Druckman 2007) despite seeking an apparent diversity of political information (Mouakket 2015).

A series of different factors, therefore, are pertinent in understanding how social network heterogeneity might translate into polarisation. First, those who possess a high degree of exposure to political information more easily take part in political discussions (Binder, Howes, and Smart 2012). Additionally, the influence of political information that one then encounters on social networks depends on the depth and level of discussion that individuals engage in (Buglass et al. 2016). This means that the simple act of being exposed to diverse political views doesn't necessarily mean that information will be allocated more weight as regards to determining one's political opinions and viewpoints. Second, reflective thinking is stimulated when individuals in social networks try to make sense of new ideologies they encounter through discussion (Johnson et al. 2013). The frequency of such discussions affects the criticality and usefulness of information encountered within individual networks (Garrett, Carnahan, and Lynch 2013). People tend to comprehend new information more easily and carefully as they anticipate discussion with those of opposing viewpoints (Lee 2012). Therefore, the relationship between social network heterogeneity and the polarisation of opinions is also determined by the frequency of political discussions individuals have on daily basis (Garrett, Carnahan, and Lynch 2013; Lee 2012). Constant exposure may mean desensitisation and thus less polarisation.

\section{Methodology}

To operationalise the three hypotheses outlined above, a cross-sectional survey of respondents from two Kenyan counties was used. The WhatsApp-friendly survey achieved a 
total of 226 respondents via WhatsApp platforms, representing a response rate of 11.9 per cent. Respondents were derived from public WhatsApp group forums through online invitation links related to Nakuru and Nairobi counties. The two counties were selected due to their cosmopolitan nature. Eleven WhatsApp groups with governance and political titles were then selected. Owing to the 256-membership cap, research was only carried out in WhatsApp groups with capacity for the researcher to join. With administrator's acknowledgements, followed by a short introduction of the research purpose to members, random probability sampling was used to select individual respondents from the various WhatsApp groups. This was followed by an invitation to selected respondents to join the researcher's WhatsApp group. Having clicked and joined the group, respondents accessed the survey from the platform. A consent form was attached at the beginning of the survey before they proceeded to answer the survey questions. Through a selective deletion formula, missing cases were removed from the survey and the quality of data was enhanced.

\section{Measuring Social Network Heterogeneity}

To measure social network heterogeneity in the WhatsApp group we profiled participants according to the following: gender (male/female), ethnicity (tribal identification-Kikuyu, Kalenjin, Luo, Luhya), class (living standard measure), ${ }^{1}$ party affiliation (Jubilee, NASA, AMANI, etc.), region of origin (different sub-counties demarcation) and religious identification (Muslim, Christian, other). A variance index score was then established for each of the six variables. This was then aggregated to summarise the six variables under study as relates to social network heterogeneity $(\mathrm{SD}=6.23, \mathrm{M}=10.33$, Range $=0-16$, Cronbach's $=0.79$ ). Having graded the diversity elements above, respondents were also asked if social network heterogeneity existed in their WhatsApp group.

\section{Measuring the Use of WhatsApp}

The use of WhatsApp was measured by asking the amount of time (hours; range two-hourly) individuals spent using it (Ellison, Lampe, and Steinfield 2007). Ten time slots were combined into one single factor and averaged to create an index of WhatsApp use (Cronbach's alpha 1/4 0.84, M 1/4 2.07, SD 1/4 0.65). Various dimensions of WhatsApp use were also considered, including posting of new items, commenting on news and discussing politics. Each of the items stated above was measured through one question - the frequency 
with which individuals engaged in each activity using WhatsApp (talking politics: $M=1.20$, $\mathrm{SD}=0.79$, range $=0-2 ;$ posting news: $\mathrm{M}=1.54, \mathrm{SD}=1.00$, range $=0-2$; getting news: $\mathrm{M}=$ $1.15, \mathrm{SD}=1.07$, range $=0-2)$. How frequently respondents were exposed to diverse news sources through posting news, discussing politics and commenting on news was also measured.

\section{Measuring Polarisation}

Three types of polarisation, (ethnic, ideological and party), were measured using methods adopted and contextualised from Pattie and Johnston (2016) and Stroud (2010). Ethnic polarisation was measured through the identification of the ethnic origins and the variance in political opinions that are held in view of one's ethnic inclinations. Respondents were required to qualify statements including "individuals in my WhatsApp group make arguments in support of their ethnic tribe" and "ethnicity issues come up in many political discussions in our WhatsApp group." Answers were ranked on a 5-point scale ranging from one (strongly disagree) to five (strongly agree). The scores on the five items were averaged to formulate an index of ethnic polarisation (Cronbach's alpha 1/4 0.83, M 1/4 2.88, SD 1/4 0.57). Ideological polarisation targeted specifically cherished beliefs around the dispensation of county resources. Ideological polarisation was connected to four themes: resource management; favouritism; access to resources and efficacy. Examples of such statements included: "Our county resources are not well managed"; "favouritism in resource distribution exists at the county level"; "I have no say in how county government distributes development resources." Similarly, responses were ranked on a 5-point scale ranging from one (strongly disagree) to 5 (strongly agree). The scores on the five items were averaged to formulate an index of ideological polarisation (Cronbach's alpha 1/4 0.81, M 1/4 3.82, SD 1/4 0.67). Party polarisation using a model similar to the feeling thermometer index of political parties (Lee et al. 2014) measured the level of polarisation. Some questions included the following: "individuals in my WhatsApp group support all their party manifesto whether good or bad"; "the most heated discussions in my WhatsApp group are party related arguments." Respondents were asked to report on a 5-point scale ranging from one (strongly disagree) to five (strongly agree). The five items were combined into a single factor, and the items were averaged to create an index of party polarisation (Cronbach's alpha 1/4 0.88, M 1/4 3.42, SD 1/4 0.58). 


\section{Results}

An ordinary least squares regression model was used to understand the relationship between heterogeneity factors as predictor variables and social network heterogeneity as the response variable. The first hypothesis was whether WhatsApp as a social networking site is reflective of the social network heterogeneity of its users. In this respect, the analysis in Table 1 below presents the heterogeneity factors with social network heterogeneity. The results indicate that the majority of variables positively contributed to social network heterogeneity of the various WhatsApp groups surveyed.

Table 1: Regression analysis of social media network heterogeneity, unstandardised (SE)a

\begin{tabular}{|lc}
\hline Predictor Variable & SNSs Network Heterogeneit \\
Respondent's age & $-0.09(0.02)^{* *}$ \\
Gender identity & $-0.23(0.41)$ \\
Ethnic identity & $0.57(0.03)^{*}$ \\
Religious identity & $0.47(0.02)^{*}$ \\
Level of education & $0.45(0.023)^{*}$ \\
Party affiliation & $0.13(0.05)^{*}$ \\
Region of origin & $0.50(0.00)^{* *}$ \\
Political discussion & $0.65(0.43)^{*}$ \\
Class identity & $0.43(0.04)^{*}$ \\
SNSs size & $0.10(0.00)$ \\
Social network heterogeneity & $1.00(0.00)^{* * *}$ \\
N = 226, R2 = 0.19. & $* \mathrm{p}<.05 . * * \mathrm{p}<.005 . * * * \mathrm{p}<.001$ \\
The **values in brackets show the statistical & \\
significance &
\end{tabular}

Ethnic identity, level of education, party affiliation, region of origin, political discussion, class identity, and size of social networking site contributed positively to the social networking heterogeneity of the WhatsApp group. This means that for every unit increase in the number of ethnic identities within the social networking site, the level of social network heterogeneity increases by 0.57 and is statistically significant. The same interpretation applies to all other variables including religious identity, where a unit increase in the number of religious identities on the WhatsApp group results in 0.47 increase in social networking heterogeneity - a significant value. The same positive relationship exists for party affiliation (0.13) where the value is significant. The only two variables that impact social networking heterogeneity in a negative way are age and gender. Understandably, age is less of an influence on the degree of social networking heterogeneity due to the demographic profile of 
average social media users and political participants in Kenya. However, gender is a very critical component of social network heterogeneity. This negative value for gender $(-0.23)$, which is not statistically significant, is somewhat puzzling. Despite being statistically insignificant, gender is a critical component of social network heterogeneity and further research is needed to understand this outcome.

The findings also reveal an important element of Kenyan sociopolitical fabric - that a randomised grouping in social networking sites largely reflects the social network heterogeneity in society in terms of the religious, political, ideological, class, regional and ethnic components. The above findings, therefore, have a bearing on the use of public WhatsApp groups as echo chambers or to enhance individuals' selective exposure as discussed by Eveland and Hively (2009) and Ponder and Haridakis (2015).

The second hypothesis was that the usage of social networking sites, including posting, obtaining and commenting on political news influences social network heterogeneity. Testing this relationship involved looking at two aspects: the first is direct and the second is the indirect techniques of analysis. This research employed direct tests as used by Binder, Howes, and Smart (2012) to understand the mediating relationship by looking at the degree of changes in the association between the independent variables. According to Carter et al. (2014), this method of analysis creates a number of advantages; it allows testing of multiple intervening variables while at the same time controlling the association between the variables themselves. Owing to the three mediators (posting, discussing, and commenting) considered in this hypothesis, the analysis used a multiple mediation analysis with a 95 per cent confidence interval of the relationship with the three mediating variables.

Table 2: WhatsApp and social network heterogeneity: Posting, discussing and commenting as mediating factors

\begin{tabular}{|lcc|}
\hline Activity & Use of WhatsApp & Social Network Heterogeneity \\
Posting news & $0.34^{*}$ & $0.66^{*}$ \\
Political discussion & $0.50^{*}$ & $0.48^{*}$ \\
Commenting on news & $0.56^{*}$ & $0.44^{*}$ \\
$\mathrm{~N}=226$ & & \\
\hline
\end{tabular}

The analysis indicated that the effects of use of social networking sites on the SNSs network heterogeneity variable was largely influenced by the specific SNS usage patterns of the 
individual users. The results in Table 2 above interpretatively mean that a 34 per cent increase in the use of WhatsApp for posting news will contribute to a 66 per cent increase in social network heterogeneity. This strongly suggests that posting news in public WhatsApp groups increases exposure to diverse perspectives. News originates from politically diverse mainstream sites and creates the incidental exposure referred to above. Although individuals may intentionally and consciously avoid information contrary to what they believe, exposure to counter-attitudinal political information can be inevitable in open WhatsApp groups. A 50 per cent increase in the use of WhatsApp for political discussions translates to a 48 per cent increase in social network heterogeneity. Thus, discussion in SNSs also allows individuals to inadvertently encounter and discover opinion-challenging information online. This happens unless conscious efforts are made to avoid it. A 56 per cent increase in news commenting translates to a 44 per cent increases social network heterogeneity. Collectively, these results mean a lack of network heterogeneity in a social networking site can be mediated to some extent by the consumption, commenting and discussion of news from diverse news platforms. This is important because individuals then become exposed to varied perspectives, viewpoints and opinions which they would otherwise miss in echo-chamber settings. These results support the findings of Binder, Howes, and Smart (2012) who found that news packaging for online platforms are brief, inviting and often controversial in an enticing way, which attracts interactive commenting and discussion. On platforms like WhatsApp, the threat of controversial discussion and topics are often hard to ignore. Hence, as Thelwall (2009) has commented, the evaluation of content by users is shaped through active contributions and political discussion over SNSs. According to Kim, Chen, and de Zúñiga (2013), social media activities like commenting, tagging and posting potentially promote exposure to diverse information and, consequently, enhance network heterogeneity among individuals. The results, therefore, support the second hypothesis.

The third hypothesis was that an association exists between social network heterogeneity and polarisation (ethnic, party and ideological polarisation). To test this hypothesis, the analysis used three dependent variables to measure the level of polarisation: ethnic polarisation, ideological (around resources) polarisation and party polarisation. The results of this regression analysis are shown in Table 3 below. 
Table 3: Regression analysis on use of WhatsApp, social networking heterogeneity and polarisation

\begin{tabular}{|c|c|c|c|}
\hline Predictor Variable & $\begin{array}{c}\text { Ethnic } \\
\text { Polarisation }\end{array}$ & $\begin{array}{l}\text { Ideological } \\
\text { Polarisation }\end{array}$ & Party Polarisation \\
\hline Respondents age & $-0.11(0.02)^{* * *}$ & $-0.24(0.02)^{* * *}$ & $-0.17(0.02)^{* * *}$ \\
\hline Gender (male and female) & $-0.23(0.41)$ & $-0.23(0.41)$ & $-0.23(0.41)$ \\
\hline Ethnic identity & $0.74(0.03)^{*}$ & $0.22(0.13)^{*}$ & $0.65(0.02)^{*}$ \\
\hline Religious identity & $0.07(0.10)$ & $0.14(0.25)$ & $0.43(0.22)$ \\
\hline Level of education & $0.32(0.03)$ & $0.33(0.12)$ & $0.21(0.31)$ \\
\hline Party affiliation & $0.15(0.18)$ & $0.19(0.65)$ & $0.63(0.05)$ \\
\hline Region of origin & $0.25(0.51)$ & $0.25(0.56)$ & $0.50(0.41)$ \\
\hline Political discussion & $0.32(0.26)^{*}$ & $0.17(0.32)^{*}$ & $0.54(0.42)^{*}$ \\
\hline Class ideology & $0.54(0.24)^{*}$ & $0.67(0.04)^{*}$ & $0.54(0.24)^{*}$ \\
\hline SNSs size & $-0.01(0.01)$ & $-0.01(0.01)$ & $-0.01(0.01)$ \\
\hline Posting news & $-0.19(0.05)$ & $-0.23(0.17)$ & $-0.09(0.43)$ \\
\hline Commenting on news & $-0.44(0.12)^{* * *}$ & $-0.55(0.12)^{* * *}$ & $-0.61(0.12)^{* * *}$ \\
\hline $\begin{array}{ll}\text { Social network } & \text { neterogeneity }\end{array}$ & $0.35(0.07)^{*}$ & $0.44(0.01)^{*}$ & $0.43(0.00)^{*}$ \\
\hline \multicolumn{4}{|l|}{$\mathbf{R}^{2}$} \\
\hline $\begin{array}{l}\mathrm{N}=226 \text {, list-wise. } \mathrm{R} 2= \\
0.19 .\end{array}$ & p $<.05 . * * p<$ & $<.001$ & \\
\hline
\end{tabular}

The study found that the various aspects of social network heterogeneity in WhatsApp groups affect the three levels of polarisation in different magnitudes, as noted in Table 3 above. Evidently, various heterogeneity factors like ethnic identity, religious identity, party affiliation, region of origin, class ideology and political discussion significantly influenced ethnic, ideological and party polarisation. It is also critical to consider how ethnic identity influences ethnic polarisation, where the value 0.74 is significant, class ideology influences ideological polarisation around resources, where the value 0.67 is significant, and party affiliation influenced party polarisation, with the value 0.63 being statistically significant as well. Ultimately, the aggregated social networking heterogeneity which is a combination of all variables was found to influence the different forms of polarisation in varied magnitudes as well. For ethnic polarisation, the value 0.35 is statistically significant. This means that a unit increase in social networking heterogeneity increases ethnic polarisation by 0.35 units. A unit increase in social networking heterogeneity leads to a 0.44 unit increase in ideological polarisation $(\mathrm{P}=0.01 \leq 0.05)$ and the same applies to party affiliation, with the value 0.43 being statistically significant. Considering the above findings, it is important to point out that a randomised collection of WhatsApp group members in a county platform naturally attracts heterogeneous individuals. The results in Table 3 above, therefore, indicate that polarisation is inevitable in SNS platforms that reflect the composition of the societies that they exist in. 
The argument by Pattie and Johnston (2016) that any form of heterogeneity creates the potential for polarisation is strongly supported. However, the extent of polarisation depends on many factors, including the context and culture around which such social networking sites are formed. This evidently happens regardless of the type of SNSs platform.

\section{Discussion}

The focus of this research has been to examine whether WhatsApp as a social networking site is reflective of the social network heterogeneity of its users. Second, we sought to understand how the usage of social networking sites, including posting political news, obtaining political news and commenting about political news, influences social network heterogeneity. Lastly, we analysed whether any association exists between social network heterogeneity and polarisation. The analysis and findings show that the randomised composition of WhatsApp groups through public links does, indeed, reflect a form of social network heterogeneity. Heterogeneity in WhatsApp groups is reflected in terms of gender, religious identity, ethnic identity, class identity, party affiliation and region of origin. Unlike close-knit, echo chamber like social networks, public WhatsApp groups afford a diversity that is reflective of the societal composition of cosmopolitan counties. Social network heterogeneity is critical and its potential to influence political discussions, participatory interests and efficacy is a subject that has been least studied. Some scholars have, however, found that the diverse composition of SNS platforms means multiple sources of information (Eveland and Hively 2009) and alternative perspectives (Dylko 2013) abound, both of which are important in enhancing political discussions and participatory interests. Kim, Chen, and de Zúñiga (2013) noted that diversity in SNS platforms is a proxy for the prevalence of divergent and often conflicting political values and views. Public displays of personal political stances and positions may yield social disapproval according to Buglass et al. (2016) and can result in interpersonal conflict due to likely disagreements (Hyun and Kim 2015). However, these arguments fail to distinguish between political activities on SNS and the process of image management and self-presentation. This happens when what an individual presents on their SNS platforms is not what they believe in or stand for (Touré-Tillery and Fishbach 2014) and this is done to receive peer approval or to hide their unpopular perspectives. These findings are consistent with those of Lee et al. (2014) who found that frequent use of social networking sites such as Facebook or Twitter predisposes individuals to having diverse networks. The diverse networks are created by the nature of the formation and the interaction within the platform and sometimes this happens without an individual's control. Importantly, SNS heterogeneity 
facilitates incidental exposure to new and diverse information as argued by Tewksbury, Weaver, and Maddex (2001). The effect of this on an individual and to the process of political participation is critical. Heterogeneous viewpoints enhance cognitive reappraisal of currently held positions and views (Wojcieszak and Mutz 2009). This ideally stimulates further information-seeking behaviour among individuals from other platforms, including traditional news outlets. The findings indicate that posting, discussing and commenting on political news influence social network heterogeneity to some degree. WhatsApp as a SNS has altered information exposure dynamics and patterns, which in turn has affected the social network heterogeneity. Being an open social network, public WhatsApp groups' heterogeneous composition of individual members creates an opportunity to incidentally encounter news and political information from other news sites. This, it should be noted, is different from private, end-to-end encrypted WhatsApp groups whose admission is based on selective associations determined by the user. Similar to other SNSs, exposure to divergent views happens through comments, posts and discussions. With other digital interactive capabilities like videos, memes, clips, news and sound bites, WhatsApp has added another platform to sociopolitical participation dynamics. The rapid growth of and interconnectivity between social media platforms are more likely to positively influence and facilitate deeper forms of diversity within the SNS networks. For example, within Facebook, it is possible to join WhatsApp, Twitter and Instagram links. Inevitably, individuals will find it harder to avoid exposure to general social network heterogeneity. This can potentially reduce the socalled echo-chamber effect in online platforms. However, the risk associated with more heterogeneity in such groups is that the platform will be characterised by diverse and often conflicting norms, practices, values and expectations (Yamamoto and Kushin 2014). Whilst some studies have linked high levels of heterogeneity with increased political participation (Boulianne 2015; Kahne and Bowyer 2018; Xenos, Vromen, and Loader 2014), others have linked it with intergroup anxiety where individuals are guarded when presenting their opinions for fear of hurting others ( $\mathrm{Li}$ and Chen 2014). Heterogeneity in SNSs as related to demographic composition, private or professional relationships and kinship seems to predict higher levels of online tension (Parsons 2010).

The findings outlined above indicate that heightened social network heterogeneity in SNSs does not necessarily mean that individuals become less polarised, more receptive and openminded. It equally does not mean that they will be more moderate in their attitudes toward political matters, especially in historically polarised contexts like Kenya. These arguments 
are well reflected in the findings regarding the third hypothesis that indicates that social network heterogeneity influences party, ideological and ethnic polarisation. Further onlinebased polarisation presents a potent danger for Kenyans. Due to the legal implications of propagating hate and polarisation in offline contexts, studies reveal that it is increasingly moving online (Freedom House 2012; Ndlela and Mulwo 2017; Snow and Taylor 2015). This is likely to aggravate tensions in countries like Kenya where the social fabric is already fragile. It is, however, important to note that activities in social media are not unidimensional. The various forms of polarisations evident in the study indicate that social networking sites have a different influence and manifestation upon each type. While the research by Lee et al. (2014) found no direct evidence of a link between social media network heterogeneity and the level of opinion polarisation, this study goes further, indicating that this evidence exists in Kenya in a more categorical way. It will be increasingly important to understand how (or whether) polarisation (party, ideological and ethnic) can be mediated by regulated political discussion. This will, however, depend on whether such political discussions are characterised by meaningful engagement marked by stringent moderation and careful consideration of information. If this doesn't happen, it is possible that biased information processing will happen. Pre-existing prejudices will crowd objective discussions and deeper polarisation will be reignited. It would indeed be interesting to see how knowledge mediates the relationship between social network heterogeneity and polarisation. Although not within the scope of this study, research has shown that when individuals are more knowledgeable, they are likely to move to more extreme issue positions and hence create more polarisation (Mutahi and Kimari 2017).

Having considered the above findings, it is evident that WhatsApp as a SNS has clearly reflected aspects of social network heterogeneity and this has influenced various forms of polarisation. Nevertheless, it is important to note of some of the limitations of our study. The associations detected among the various variable pursued in the study are not necessarily suitable for making claims of causal inferences. While the study attempted to measure concepts like polarisation with statistical precision, the interpretation and understanding of such constructs are debatable. A further limitation is that political commenting, discussion and posting were measured as related to their frequency. It did not consider the attributes and dynamics of political discussion. This makes the measuring of political discussion effects difficult to qualify in absolute terms. 


\section{Conclusion}

By looking at WhatsApp, this study has extended the technological and geographical focus of research on social networking sites and polarisation. Much of the existing research on SNSs' heterogeneity has concentrated on Twitter and Facebook in particular. To some extent this also reflects the geographical bias inherent in much of the current research on political polarisation which concentrates largely on North America and Northern Europe. Our findings based on WhatsApp platforms present both similar and divergent aspects of social network heterogeneity and polarisation. With its new features, allowing its use as an instant messaging and a social networking site, WhatsApp presents news affordances slightly unique when compared to Twitter and Facebook. This illustrates the need to be alert to both technological and contextual differences when studying social network heterogeneity and polarisation. This also applies to assumption on SNS adoption and impacts as regards to polarisation. The geographical contexts, SNS features/affordances and the characteristics of online social networks in these platforms are crucial aspects that drive how and whether SNS influence polarisation. Furthermore, research on polarisation needs to do more than just examine network linkages and assume that the homogeneity/heterogeneity of networks leads to more or less polarisation respectively. It is important to understand not just the characteristics of the networks but how people use SNSs, the information received via these platforms and the interpretation of such material are crucial to shaping patterns of polarisation.

The Kenyan context offers further insights to the SNS-polarisation discussion. Whereas much of the existing popular discussion of polarisation in Western countries centres on how technology might be responsible for heightening divisions, what happens when a technology is added into an already highly polarised society such as Kenya? The research here suggests that similar to Western contexts, there is certainly a danger of emergent SNSs like WhatsApp heightening existing polarisation. Notably, in terms of political discussion online, without careful moderation, entrenched division and incivility are unlikely to add much to democratic discourse. This will become even more crucial given the growing popularity of WhatsApp platforms (and social media generally), especially amongst the young Kenyan population. There also exists considerable growth of parallel unofficial WhatsApp platforms to discuss county governance issues and owing to the end-to-end encryption features of WhatsApp, such groups are generally not open to public scrutiny. Finally, the Kenyan constitution places considerable formal emphasis on encouraging participation as a potential solution to governance problems. Social media and the Internet are often seen as important elements for 
fostering such participation amongst younger citizens. It may be that SNSs can indeed extend participation, but arguably more attention needs to focus on the quality and impact of expansion of both online and offline participatory platforms.

\section{References}

Africa Internet Users. 2017. Internet Users Statistics for Africa.

Ahn, J. 2012. "Teenagers' Experiences with Social Network Sites: Relationships to Bridging and Bonding Social Capital.” The Information Society 28 (7): 99-109. https://doi.org/10.1080/01972243.2011.649394.

Arceneaux, K., and M. Johnson. 2010. "Does Media Fragmentation Produce Mass Polarisation? Selective Exposure and a New Era of Minimal Effects.” APSA 2010 Annual Meeting Paper. Accessed November 2, 2018. https://papers.ssrn.com/sol3/papers.cfm?abstract id=1642723.

Baek, Y. M. 2015. "Political Mobilization through Social Network Sites: The Mobilizing Power of Political Messages Received from SNS Friends." Computers in Human Behavior 44: 12-9. https://doi.org/10.1016/j.chb.2014.11.021.

Berg-Schlosser, D. 1982. "Modes and Meaning of Political Participation in Kenya." Comparative Politics 14 (4): 397-415. https://doi.org/10.2307/421630.

Binder, A. R., K. E. Dalrymple, D. Brossard, and D. A. Scheufele. 2009. "The Soul of a Polarized Democracy: Testing Theoretical Linkages Between Talk and Attitude Extremity During the 2004 Presidential Election." Communications Research 36 (3): 315-40. https://doi.org/10.1177/0093650209333023.

Binder, J. F., A. Howes, and D. Smart. 2012. "Harmony and Tension on Social Network Sites: SideEffects of Increasing Online Interconnectivity." Information, Communication and Society 15 (9): 1279-297. https://doi.org/10.1080/1369118X.2011.648949.

BAKE (Bloggers Association of Kenya). 2017. State of the Internet in Kenya 2017 Report. Accessed November 2, 2018. https://www.ifree.co.ke/wp-content/uploads/2018/02/State-of-theInternet-in-Kenya-report-2017.pdf.

Bojanowski, M., and R. Corten. 2014. "Measuring Segregation in Social Networks." Social Networks 39: 14-32. https://doi.org/10.1016/j.socnet.2014.04.001.

Boulianne, S. 2015. "Social Media Use and Participation: A Meta-Analysis of Current Research." Information, Communication and Society 18 (5): 523-28. https://doi.org/10.1080/1369118X.2015.1008542.

Branch, D., and N. Cheeseman. 2006. "The Politics of Control in Kenya: Understanding the Bureaucratic-Executive State, 1952-78." Review of African Political Economy 33 (107): 1131. https://doi.org/10.1080/03056240600671183.

Brites, M. J. 2014. "Consuming the News and Building Civic Participation." Participation: Journal of Audience and Reception Studies 11 (1): 130-49. Accessed October 31, 2018. http://www.participations.org/Volume 11/Issue 1/8.pdf. 
Brundidge, J. 2010. "Encountering 'Difference' in the Contemporary Public Sphere: The Contribution of the Internet to the Heterogeneity of Political Discussion Networks." Journal of Communication 60 (4): 680-700. https://doi.org/10.1111/j.1460-2466.2010.01509.x.

Buccafurri, F., G. Lax, S. Nicolazzo, and A. Nocera. 2016. "A Model to Support Design and Development of Multiple-Social-Network Applications.” Information Sciences 331: 99-119. https://doi.org/10.1016/j.ins.2015.10.042.

Buglass, S. L., J. F. Binder, L. R. Betts, and J. D. M. Underwood. 2016. "When 'Friends' Collide: Social Heterogeneity and User Vulnerability on Social Network Sites." Computers in Human Behavior 54: 62-72. https://doi.org/10.1016/j.chb.2015.07.039.

Buglass, S. L., J. F. Binder, L. R. Betts, and J. D. M. Underwood. 2017. "Looking for Trouble: A Multilevel Analysis of Disagreeable Contacts in Online Social Networks." Computers in Human Behavior 70: 234-43. https://doi.org/10.1016/j.chb.2016.12.078.

Carpini, M. X. D., F. L. Cook, and L. R. Jacobs. 2004. "Public Deliberation, Discursive Participation and Citizen Engagement: A Review of the Empirical Literature." Annual Review of Political Science 7: 315-344. https://doi.org/10.1146/annurev.polisci.7.121003.091630.

Carrier, N., and H. H. Kochore. 2014. "Navigating Ethnicity and Electoral Politics in Northern Kenya: The Case of the 2013 Election." Journal of Eastern African Studies 8 (1): 135-52. https://doi.org/10.1080/17531055.2013.871181.

Carter, N., D. Bryant-Lukosius, A. DiCenso, J. Blythe, and A. J. Neville. 2014. "The Use of Triangulation in Qualitative Research." Oncology Nursing Forum 41 (5): 545-47. https://doi.org/10.1188/14.ONF.545-547.

Cheeseman, N., G. Lynch, and J. Willis. 2014. "Democracy and Its Discontents: Understanding Kenya's 2013 Elections.” Journal of Eastern African Studies 8 (1): 2-24. https://doi.org/10.1080/17531055.2013.874105.

Chong, D., and J. N. Druckman. 2007. "Framing Public Opinion in Competitive Democracies." American Political Science Review 101 (4): 637-55. https://doi.org/10.1017/S0003055407070554.

CRECO (Constitution and Reform Education Consortium). 2014. Model Policy Framework for Public Participation in County Governments. Accessed November 2, 2018. http://crecokenya.org/new/attachments/article/152/Creco-County-Model.pdf.

Dylko, I. B. 2013. "On the Role of Technology in Political Communication Research." Javnost: Public Journal of the European Institute for Communication and Culture 20 (1): 55-70. https://doi.org/10.1080/13183222.2013.11009108.

Ellison, N. B., C. Lampe, and C. Steinfield. 2007. "Social Network Sites and Society: Current Trends and Future Possibilities." Interactions Magazine 16 (1): 6-9.

Enjolras, B., K. Steen-Johnsen, and D. Wollebæk. 2013. "Social Media and Mobilization to Offline Demonstrations: Transcending Participatory Divides?" New Media and Society 15 (6): 890908. https://doi.org/10.1177/1461444812462844.

Eveland, W. P., and M. H. Hively. 2009. "Political Discussion Frequency, Network Size, and 'Heterogeneity' of Discussion as Predictors of Political Knowledge and Participation." Journal of Communication 59 (3): 205-24. https://doi.org/10.1111/j.14602466.2009.01412.x. 
Fabbrini, S. 2013. "The Rise and Fall of Silvio Berlusconi: Personalization of Politics and Its Limits." Comparative European Politics 11 (2): 153-71. https://doi.org/10.1057/cep.2012.18.

Fraenkel, E. 2014. "A Critical Analysis of Digital Communications and Conflict Dynamics in Vulnerable Societies." Accessed November 2, 2018. https://www.internews.org/sites/default/files/Internews_DigComminconflict_2014-11.pdf.

Freedom House. 2012. Freedom on the Net: A Global Assessment of Internet and Digital Media. Edited by S. Kelly, S. Cook and M. Truong. Accessed November 2, 2018. https://freedomhouse.org/sites/default/files/resources/FOTN\%202012\%20\%20Full\%20Report_0.pdf.

Garrett, R. K., D. Carnahan, and E. K. Lynch. 2013. "A Turn Toward Avoidance? Selective Exposure to Online Political Information, 2004-2008." Political Behavior 35 (1): 113-134. https://doi.org/10.1007/s11109-011-9185-6.

Gustafsson, N. 2012. "The Subtle Nature of Facebook Politics: Swedish Social Network Site Users and Political Participation." New Media and Society 14 (7): 1111-127. https://doi.org/10.1177/1461444812439551.

Halakhe, A. B. 2013. "R2P in Practice: Ethnic Violence, Elections and Atrocity Prevention in Kenya." Occasional Paper Series, No. 4. New York: The Global Centre for the Responsibility to Protect.

Hassan, M. 2015. "Continuity Despite Change: Kenya's New Constitution and Executive Power." Democratization 22 (4): 587-609. https://doi.org/10.1080/13510347.2013.853174.

Hyun, K. D., and J. Kim. 2015. "Differential and Interactive Influences on Political Participation by Different Types of News Activities and Political Conversation through Social Media." Computers in Human Behavior 45: 328-34. https://doi.org/10.1016/j.chb.2014.12.031.

Ji, Q. 2017. "Social Media News Use and Political Discussion: A Focus on Chinese Users' News Reception and Dissemination." Electronic News 11 (1): 3-19. https://doi.org/10.1177/1931243116672257.

Johnson, K., M. Tanner, M., N. Lalla, and D. Kawalski. 2013. "Social Capital: The Benefit of Facebook 'Friends'.” Behaviour and Information Technology 32 (1): 24-36. https://doi.org/10.1080/0144929X.2010.550063.

Kabiri, N. 2014. "Ethnic Diversity and Development in Kenya: Limitations of Ethnicity as a Category of Analysis." Commonwealth and Comparative Politics 52 (4): 513-34. https://doi.org/http://dx.doi.org/10.1080/14662043.2014.957500.

Kagwanja, P., and R. Southall. 2009. "Introduction: Kenya-A Democracy in Retreat?" Journal of Contemporary African Studies 27 (3): 259-77. https://doi.org/10.1080/02589000903216930.

Kahne, J., and B. Bowyer. 2018. "The Political Significance of Social Media Activity and Social Networks." Political Communication 35 (3): 470-93. https://doi.org/10.1080/10584609.2018.1426662.

Kamau, S. C. 2017. "Democratic Engagement in the Digital Age: Youth, Social Media and Participatory Politics in Kenya." South African Journal for Communication Theory and Research 43 (2): 128-46. https://doi.org/10.1080/02500167.2017.1327874. 
Kanyinga, K. 2014. Kenya: Democracy and Political Participation. Nairobi: Open Society Initiative of East Africa.

Kim, Y. 2015. "Does Disagreement Mitigate Polarization? How Selective Exposure and Disagreement Affect Political Polarization.” Journalism and Mass Communication Quarterly 92 (4): 915-37. https://doi.org/10.1177/1077699015596328.

Kim, Y., and H.-T. Chen. 2015. "Discussion Network Heterogeneity Matters: Examining a Moderated Mediation Model of Social Media Use and Civic Engagement." International Journal of Communication 9 (6): 2344-365.

Kim, Y., H.-T. Chen, and H. G. de Zúñiga. 2013. "Stumbling upon News on the Internet: Effects of Incidental News Exposure and Relative Entertainment Use on Political Engagement." Computers in Human Behavior 29 (6): 2607-614. https://doi.org/10.1016/j.chb.2013.06.005.

Kim, Y., S.-H. Hsu, and H. G. de Zúñiga. 2013. "Influence of Social Media Use on Discussion Network Heterogeneity and Civic Engagement: The Moderating Role of Personality Traits." Journal of Communication 63 (3): 498-516. https://doi.org/10.1111/jcom.12034.

Kim, B., and Y. Kim. 2017. "College Students' Social Media Use and Communication Network Heterogeneity: Implications for Social Capital and Subjective Well-Being." Computers in Human Behavior 73: 620-28. https://doi.org/10.1016/j.chb.2017.03.033.

Lecheler, S., M. Keer, A. R. T. Schuck, and R. Hänggli. 2015. "The Effects of Repetitive News Framing on Political Opinions over Time.” Communication Monographs 82 (3): 339-58. https://doi.org/10.1080/03637751.2014.994646.

Lee, F. L. 2012. "Does Discussion with Disagreement Discourage All Types of Political Participation? Survey Evidence from Hong Kong." Communication Research 39 (4): 543-62. https://doi.org/10.1177/0093650211398356.

Lee, J. K., J. Choi, C. Kim, and Y. Kim. 2014. "Social Media, Network Heterogeneity, and Opinion Polarization." Journal of Communication 64 (4): 702-22. https://doi.org/10.1111/jcom.12077.

Li, X., and W. Chen. 2014. "Facebook or Renren? A Comparative Study of Social Networking Site Use and Social Capital among Chinese International Students in the United States." Computers in Human Behavior 35: 116-23. https://doi.org/10.1016/j.chb.2014.02.012.

Ljepava, N., R. R. Orr, S. Locke, and C. Ross. 2013. "Personality and Social Characteristics of Facebook Non-Users and Frequent Users." Computers in Human Behavior 29 (4): 1602-607. https://doi.org/10.1016/j.chb.2013.01.026.

Loader, B. D., and D. Mercea. 2011. "Networking Democracy? Social Media Innovations and Participatory Politics." Information, Communication and Society 14 (6): 757-69. https://doi.org/10.1080/1369118X.2011.592648.

Loader, B. D., A. Vromen, and M. A. Xenos. 2014. "The Networked Young Citizen: Social Media, Political Participation and Civic Engagement." Information, Communication and Society 17 (2): 143-50. https://doi.org/10.1080/1369118X.2013.871571.

Long, J. D., K. Kanyinga, K. E. Ferree, and C. Gibson. 2013. "Choosing Peace over Democracy." Journal of Democracy 24 (3): 140-55. https://doi.org/10.1353/jod.2013.0048. 
Messing, S., and S. J. Westwood. 2014. "Selective Exposure in the Age of Social Media: Endorsements Trump Partisan Source Affiliation When Selecting News Online." Communication Research 41 (8): 1042-63. https://doi.org/10.1177/0093650212466406.

Min, S.-J. 2010. "From the Digital Divide to the Democratic Divide: Internet Skills, Political Interest, and the Second-Level Digital Divide in Political Internet Use." Journal of Information Technology and Politics 7 (1): 22-35. https://doi.org/10.1080/19331680903109402.

Mouakket, S. 2015. "Factors Influencing Continuance Intention to Use Social Network Sites: The Facebook Case." Computers in Human Behavior 53: 102-10. https://doi.org/10.1016/j.chb.2015.06.045.

Munyua, A. W. 2016. "Exploring the Multi-Stakeholder Experience in Kenya." Journal of Cyber Policy 1 (2): 206-21. https://doi.org/10.1080/23738871.2016.1249898.

Mutahi, P., and B. Kimari. 2017. "The Impact of Social Media and Digital Technology on Electoral Violence in Kenya." Institute of Development Studies Working Paper, No. 493.

Ndlela, M. N., and A. Mulwo. 2017. "Social Media, Youth and Everyday Life in Kenya." Journal of African Media Studies 9 (2): 277-90. https://doi.org/10.1386/jams.9.2.277. https://doi.org/10.1386/jams.9.2.277_1.

Nir, L. 2011. "Disagreement and Opposition in Social Networks: Does Disagreement Discourage Turnout?" Political Studies 59 (4): 674-92. https://doi.org/10.1111/j.14679248.2010.00873.x.

Osatuyi, B. 2013. "Information Sharing on Social Media Sites." Computers in Human Behavior 29 (6): 2622-631. https://doi.org/10.1016/j.chb.2013.07.001.

Parsons, B. M. 2010. "Social Networks and the Affective Impact of Political Disagreement." Political Behaviour 32 (2): 181-204. https://doi.org/10.1007/s11109-009-9100-6.

Pattie, C. J., and R. Johnston. 2016. "Talking with One Voice? Conversation Networks and Political Polarisation." The British Journal of Politics and International Relations 18 (2): 482-97. https://doi.org/10.1177/1369148115620989.

Pénard, T., and N. Poussing. 2010. "Internet Use and Social Capital: The Strength of Virtual Ties." Journal of Economic Issues 44 (3): 569-95. https://doi.org/10.2753/JEI0021-3624440301.

Ponder, J. D., and P. Haridakis. 2015. "Selectively Social Politics: The Differing Roles of Media Use on Political Discussion." Mass Communication and Society 18 (3): 281-302. https://doi.org/10.1080/15205436.2014.940977.

Price, V., J. N. Cappella, and L. Nir. 2002. "Does Disagreement Contribute to More Deliberative Opinion?" Political Communication 19 (1): 95-112. https://doi.org/10.1080/105846002317246506.

Rathnayake, C., and J. S. Winter. 2017. "Examining the Link Between Social Media Uses and Gratifications, and Political Tolerance and Dogmatism." Policy and Internet 9 (4): 444-66. https://doi.org/10.1002/poi3.157.

Rojas, H., and E. Puig-i-Abril. 2009. "Mobilizers Mobilized: Information, Expression, Mobilization and Participation in the Digital Age." Journal of Computer-Mediated Communication 14 (4): 902-927. https://doi.org/10.1111/j.1083-6101.2009.01475.x. 
Scheufele, D. A., B. W. Hardy, D. Brossard, I. S. Waismel-Manor, and E. Nisbet 2006. "Democracy Based on Difference: Examining the Links Between Structural Heterogeneity, Heterogeneity of Discussion Networks, and Democratic Citizenship." Journal of Communication 56 (4): 728-53. https://doi.org/10.1111/j.1460-2466.2006.00317.x.

Snow, C., and W. Taylor. 2015. Media, Discussion and Attitudes in Fragile Contexts. BBC Media Action. Accessed November 2, 2018.

http://downloads.bbc.co.uk/mediaaction/pdf/research/media-discussion-attitudes-fragilecontexts-report.pdf.

Souter, D., and M. Kerrets-Makau. 2012. Internet Governance in Kenya-An Assessment for the Internet Society. ICT Development Associates. Accessed November 2, 2018. https://www.researchictafrica.net/multistake/Souter_Kerretts-Makau_2012__Internet_governance_in_Kenya__an_assessment_for_the_Internet_Society.pdf.

Stroud, N. J. 2010. "Polarization and Partisan Selective Exposure." Journal of Communication 60 (3): 556-76. https://doi.org/10.1111/j.1460-2466.2010.01497.x.

Tewksbury, B. D., A. J. Weaver, and B. D. Maddex. 2001. "Accidently Informed: Incidental News Exposure to World Wide Web.” Journal of Media and Communications Studies 78 (3): 53354.

Touré-Tillery, M., and A. Fishbach. 2014. "How to Measure Motivation: A Guide for the Experimental Social Psychologist." Social and Personality Psychology Compass 8 (7): 32841. https://doi.org/10.1111/spc3.12110.

Vaccari, C., A. Valeriani, P. Barberá, R. Bonneau, J. T. Jost, J. Nagler, and J. A. Tucker. 2015. "Political Expression and Action on Social Media: Exploring the Relationship Between Lower- and Higher-Threshold Political Activities among Twitter Users in Italy." Journal of Computer-Mediated Communication 20 (2): 221-39. https://doi.org/10.1111/jcc4.12108.

Valenzuela, S., A. Arriagada, and A. Scherman. 2012. "The Social Media Basis of Youth Protest Behavior: The Case of Chile." Journal of Communication 62 (2): 299-314. https://doi.org/10.1111/j.1460-2466.2012.01635.x.

Vissers, S., and D. Stolle. 2014. "The Internet and New Modes of Political Participation: Online Versus Offline Participation." Information, Communication and Society 17 (8): 937-55. https://doi.org/10.1080/1369118X.2013.867356.

Weeks, B. E., D. S. Lane, S. S. Lee, D. H. Kim, and N. Kwak. 2017. "Incidental Exposure, Selective Exposure, and Political Information Sharing: Integrating Online Exposure Patterns and Expression on Social Media." Journal of Computer-Mediated Communication 22 (6): 36379. https://doi.org/10.1111/jcc4.12199.

Weir, G. R. S., F. Toolan, and D. Smeed. 2011. "The Threats of Social Networking: Old Wine in New Bottles?" Information Security Technical Report 16 (2): 38-43. https://doi.org/10.1016/j.istr.2011.09.008.

Wicks, R. H., J. L. Wicks, and S. A. Morimoto. 2014. "Partisan Media Selective Exposure During the 2012 Presidential Election.” American Behavioral Scientist 58 (9): 1131-143. https://doi.org/10.1177/0002764213506208. 
Wojcieszak, M. E. 2010. “'Don’t Talk to Me': Effects of Ideologically Homogeneous Online Groups and Politically Dissimilar Offline Ties on Extremism." New Media and Society 12 (4): 63755. https://doi.org/10.1177/1461444809342775.

Wojcieszak, M. E., and D. C. Mutz. 2009. "Online Groups and Political Discourse: Do Online Discussion Spaces Facilitate Exposure to Political Disagreement?" Journal of Communication 59 (1): 40-56. https://doi.org/10.1111/j.1460-2466.2008.01403.x.

World Bank. 2012. Devolution Without Disruption; Pathways to a Successful New Kenya. Washington, DC: World Bank. Accessed November 2, 2018. http://documents.worldbank.org/curated/en/534071468272361395/Main-report.

Yamamoto, M., and M. J. Kushin. 2014. "More Harm Than Good? Online Media Use and Political Disaffection Among College Students in the 2008 Election." Journal of Computer-Mediated Communication 19 (3): 430-45. https://doi.org/10.1111/jcc4.12046.

Xenos, M., A. Vromen, and B. D. Loader. 2014. "The Great Equalizer? Patterns of Social Media Use and Youth Political Engagement in Three Advanced Democracies." Information, Communication and Society 17 (2): 151-67. https://doi.org/10.1080/1369118X.2013.871318.

Xu, B., L. Liu, and W. You. 2011. "Importance of Tie Strengths in the Prisoner's Dilemma Game on Social Networks." Physics Letters A 375 (24): 2269-273. https://doi.org/10.1016/j.physleta.2011.05.014.

Zeleza, T. P. 2010. "The Developmental and Democratic Challenges of Postcolonial Kenya." UCLA: James S. Coleman African Studies Center. Accessed November 2, 2018. https://pub-jscholprd.escholarship.org/uc/item/3bh758jz.

Zhang, W., T. J. Johnson, T. Seltzer, and S. L. Bichard. 2010. "The Revolution Will be Networked: The Influence of Social Networking Sites on Political Attitudes and Behavior." Social Science Computer Review 28 (1): 75-92. https://doi.org/10.1177/0894439309335162. 